\title{
A Compact Rectangular Monopole Antenna with Enhanced Bandwidth.
}

\author{
Darshana R. Suryawanshi. ${ }^{1}$, Prof. Bharati A. Singh. ${ }^{2}$ \\ ${ }^{1,2}$ (Electronics \& Telecommunication Department, K. J. Somaiya college of Engineering, Vidyavihar,Mumbai- \\ 77 /Mumbai University, India)
}

\begin{abstract}
A Compact rectangular monopole antenna with enhanced bandwidth is presented. Achieved percentage bandwidth is $79.37 \%$, ranging from $5.228 \mathrm{GHz}$ to $12.248 \mathrm{GHz}$ for VSWR $<2$. Proposed antenna comprises a radiating rectangular patch of size $7 \mathrm{~mm} X 8 \mathrm{~mm}$, finite ground plane of size $15 \mathrm{~mm} X 7 \mathrm{~mm}$, antenna is feed with $50 \Omega$ microstrip feed line of dimension $3.04 \mathrm{~mm} X 7.6 \mathrm{~mm}$ .The total size of proposed antenna is $15 \mathrm{~mm} X 15.6 \mathrm{~mm} X 1.59 \mathrm{~mm}(W X L X h)$ is designed and simulated using ZELAND IE3D simulation software with FR4 substrate of dielectric constant value 4.4 with loss tangent 0.02 .
\end{abstract}

Keywords: Microstrip feed, Monopole antennas, Percentage bandwidth .

\section{INTRODUCTION}

The microstrip patch antennas are of great importance because of their eye catching attributes as they are light weight, low profile, inexpensive and top of all, quick and simple to fabricate [1]. Despite the progressions in designing microstrip antennas, the major issues are bandwidth, gain and radiation losses which limit their performance. To shorten the limitations, different design techniques have been implemented to achieve enhanced bandwidth using microstrip patch antennas[1].

In last few decades several research on different techniques of enhancing Bandwidth of microstrip antenna (MSA) has been done. The different techniques like by making slot in radiating patch[1,2] , stacking of MSA[1,3], defected ground structures(DGS)[4] and Variation of size of MSA and variation of size of ground plane leading to monopole antenna to give more enhanced band width[1,5].

Current trends in portable and mobile communications are towards greater numbers of different systems often with wider bandwidths, operating within a single device. Antenna systems for these devices need to be capable of operating over a wide frequency range or multiple frequency bands. Portable and mobile applications also require antennas to be optimised with respect to radiation pattern, efficiency and physical size.

Monopole antennas have found widespread applications in wireless mobile communication systems. because of their simple structure, low costs, and omnidirectional radiation pattern. The designs of monopole antennas mainly include two types, which are respectively metal plate monopole and planar printed monopole. The former needs a perpendicular ground plane, resulting in the increasing of antenna volume and the inconvenience for integrating with monolithic microwave integrated circuits, whereas the latter avoids the perpendicular ground plane[6]. Therefore, planar printed monopole antenna is more compact in structure and possesses advantages in the portable devices applications.

In this paper a novel simple and a compact rectangular monopole antenna with microstrip feed is presented.\%Bandwidth of $79.37 \%$ has been achieved, with finite ground plane. the design and simulated results are presented for dielectric substrate of value 4.4 with loss tangent 0.02 . Bandwidth ranging from $5.228 \mathrm{GHz}$ to $12.248 \mathrm{GHz}$ for VSWR $<2$. The proposed antenna is designed and simulated using ZELAND IE3D simulation software .

\section{ANTENNA DESIGN}

A rectangular microstrip antenna (RMSA) was designed with resonance frequency $(f r)=5.4 \mathrm{GHz}$, dielectric constant $(\varepsilon r)=4.4$, substrate thickness $=1.59 \mathrm{~mm}$, loss tangent $(\tan \delta)=0.02[8]$, width of RMSA is $16.9 \mathrm{~mm},(1)$.Length of RMSA is $12.68 \mathrm{~mm},(5)$. Width and length of ground plane of RMSA are $26.44 \mathrm{~mm}$ and $22.228 \mathrm{~mm}$ respectively,(6), (7) . Fig.1 shows Designed RMSA bandwidth obtained is $288 \mathrm{MHz}$ ranging from 5.216GHz-5.506GHz shown in Fig.2 and VSWR plot in Fig.3. Simulation is done in ZELAND IE3D Simulator. RMSA with finite and infinite ground plane are simulated.

Microstrip Line Feeding technique is used to feed the patch. In this type of feed technique , a conducting strip is connected directly to the edge of the microstrip patch .The conducting strip is smaller in width as compared to the patch and this kind of feed arrangement has the advantage that the feed can be etched 
on the same substrate to provide a planar structure. Width of microstrip feed line is $3.04 \mathrm{~mm},(12)$. Length of microstrip feed line 7.6mm,(15).[7]

By modifying width and length of RMSA and by reducing the size of finite ground plane monopole antenna in fig. 4 is shown. It gives enhanced bandwidth $6960 \mathrm{MHz}$ ranging from $5.288 \mathrm{GHz}-12.248 \mathrm{GHz}$ as in Fig.5.VSWR plot in Fig.6

table.1 shows the comparison of bandwidths of RMSA and Monopole antenna with microstrip feed line. Figs.2,5 are simulated return loss in db Vs frequency .

\section{Indentations and Equations}

$$
\begin{aligned}
& \mathrm{W}=\frac{\mathrm{C}}{2 f r} \sqrt{\frac{2}{\varepsilon r+1}} \\
& \text { creff }=\frac{\varepsilon r+1}{2}+\frac{\varepsilon r-1}{2}\left[1+12 \frac{h}{w}\right]^{-1 / 2} \\
& \text { Leff }=\frac{\mathrm{C}}{2 \text { fr } \sqrt{\varepsilon e f f}} \\
& L L=0.412 \mathrm{~h} \frac{(\varepsilon r e f f+0.3)\left(\frac{w}{h}+0.264\right)}{(\text { Ereff }-0.258)\left(\frac{w}{h}+0.8\right)} \\
& W_{g}=6 \mathrm{~h}+\mathrm{W} \\
& L_{g}=6 \mathrm{~h}+\mathrm{L} \\
& Z_{0}=\frac{60}{\sqrt{\varepsilon e f f}} \ln \left(8 \frac{h}{w}+\frac{w}{4 h}\right)
\end{aligned}
$$

Where

$$
\text { Eeff }=\frac{\varepsilon r+1}{2}+\frac{\varepsilon r-1}{2}\left[\left(1+12 \frac{h}{w}\right)^{-\frac{1}{2}}+0.004\left(1-\frac{w}{h}\right)^{2}\right] \quad \ldots \ldots \ldots \ldots . \text { for } \frac{w}{h} \leq 1
$$

or

$$
Z_{0}=\frac{120 \pi}{\sqrt{\varepsilon e f f}\left[\frac{w}{h}+1.393+0.667 \ln \left(\frac{w}{h}+1.444\right)\right]}
$$

where

$$
\varepsilon \text { eff }=\frac{\varepsilon r+1}{2}+\frac{\varepsilon r-1}{2}\left(1+12 \frac{h}{w}\right)^{-\frac{1}{2}} \ldots \ldots \ldots \ldots \ldots \text { for } \frac{w}{h} \geq 1
$$

OR

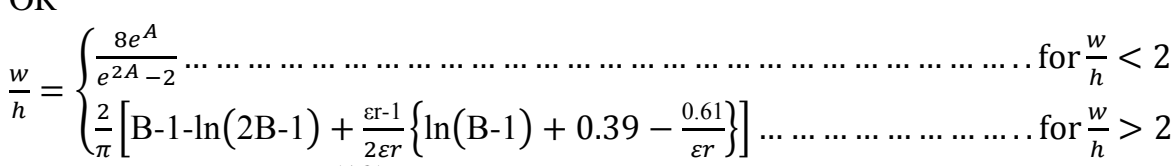

where

$\mathrm{A}=\frac{z_{0}}{60} \sqrt{\frac{\varepsilon \mathrm{r}+1}{2}}+\frac{\varepsilon \mathrm{r}-1}{\varepsilon \mathrm{r}+1}(0.23+$

$\left.\frac{0.11}{\varepsilon r}\right)$

and

$\mathrm{B}=\frac{377 \pi}{2 Z_{0} \sqrt{\varepsilon r}}$

4)

$l=\frac{90^{0}\left(\pi / 180^{0}\right)}{\sqrt{\varepsilon_{e}} k_{0}}$ 
where

$k_{0}=\frac{2 \pi f}{c}$

$\% \mathrm{~B}=2 \frac{f_{H}-f_{L}}{f_{H}+f_{L}}$

\section{Figures and Tables}

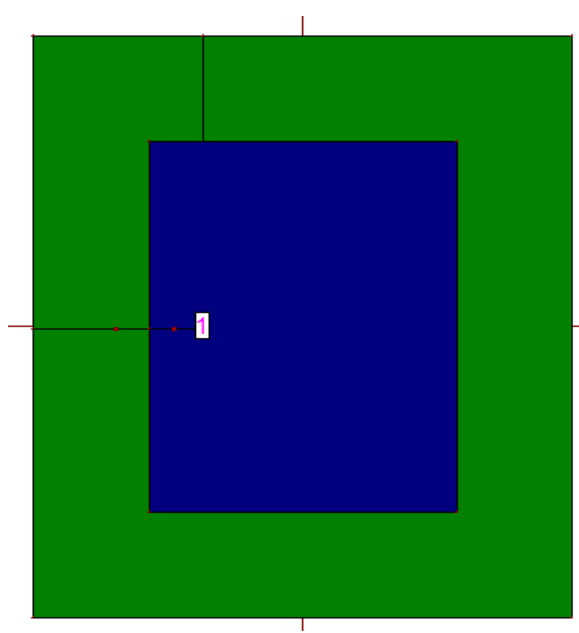

Fig.1

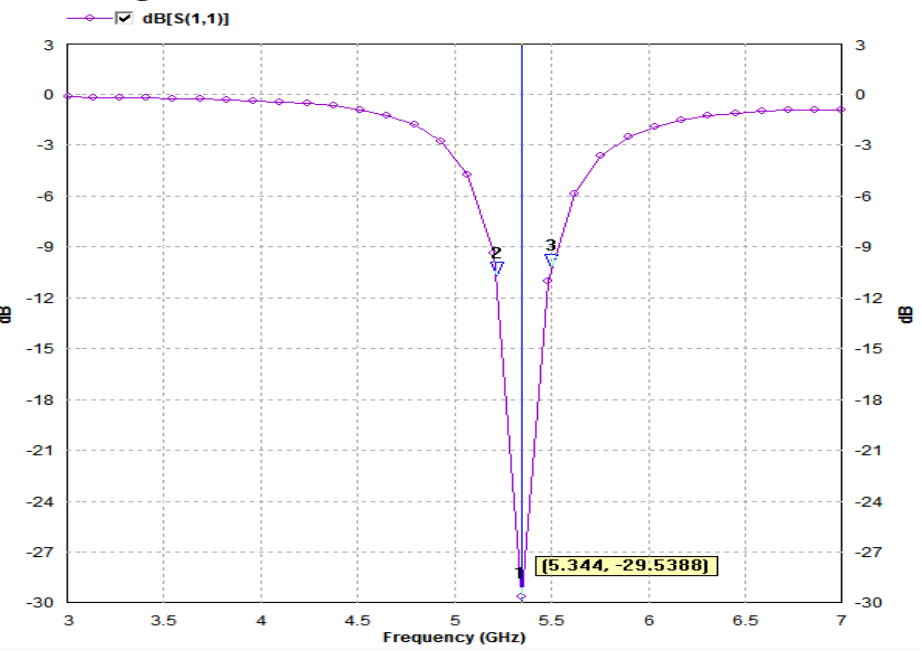

Fig.2



Fig.3

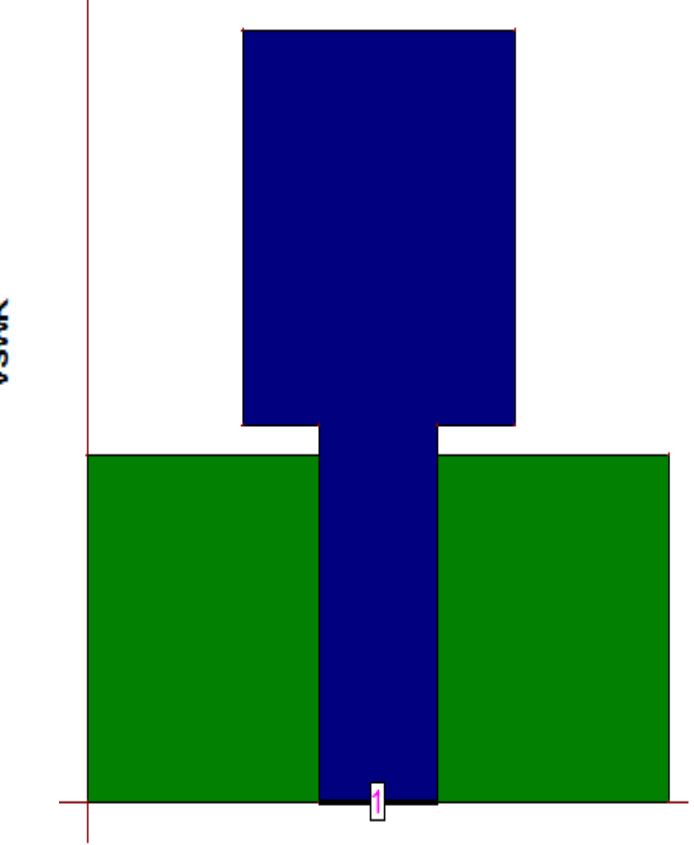

Fig.4 


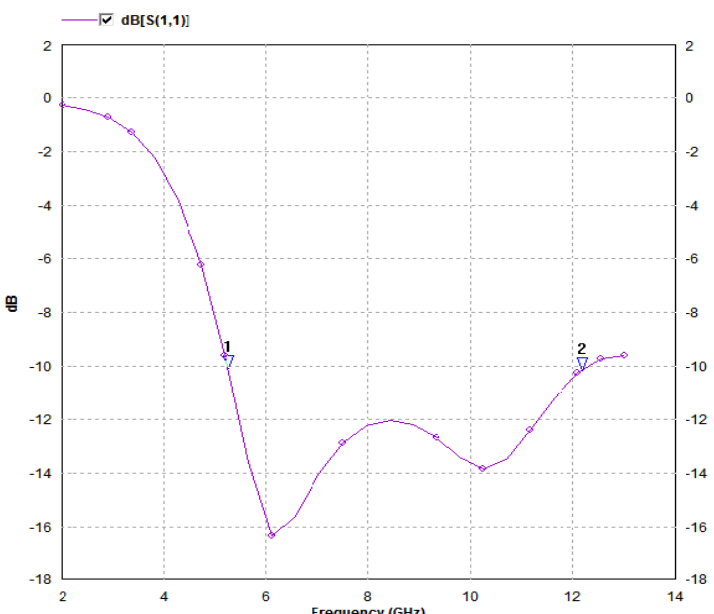

Fig. 5

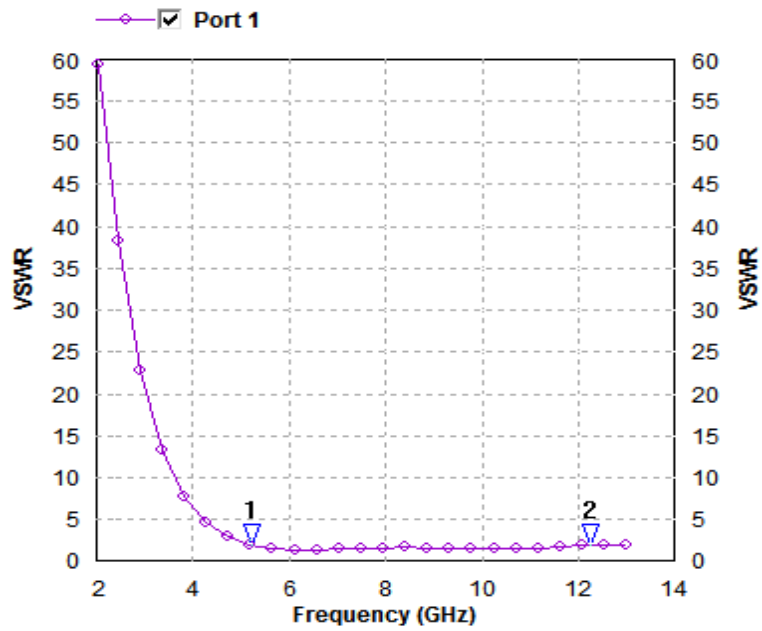

Fig.6

Table. 1

\begin{tabular}{|c|c|c|c|c|c|}
\hline $\begin{array}{c}\text { Sr. } \\
\text { No. }\end{array}$ & Antenna structure & Bandwidth & Range & \%andwidth & $\begin{array}{c}\text { Size } \\
(\text { WxLxh }) \mathrm{mm}^{3}\end{array}$ \\
\hline 1 & RMSA with finite ground plane & $288 \mathrm{MHz}$ & $5.216 \mathrm{GHz}-5.506 \mathrm{GHz}$ & $5.41 \%$ & 934.11 \\
\hline 2 & Monopole antenna & $6960 \mathrm{MHz}$ & $5.288 \mathrm{GHz}-12.248 \mathrm{GHz}$ & $79.37 \%$ & 372.06 \\
\hline
\end{tabular}

\section{Conclusion}

A simple microstrip feed line has been introduced and applied to feed rectangular monopole antenna. A compact rectangular monopole antenna with enhanced bandwidth is designed and simulated using ZELAND IE3D Simulator. percentage bandwidth achieved is $79.37 \%$, ranging from $5.228 \mathrm{GHz}$ to $12.248 \mathrm{GHz}$ for VSWR $<2$.

\section{References}

[1] Girish Kumar and K P Ray, 'Broadband Microstrip Antennas', Artech House, 2003.

[2] Kin-Fai Tong, Kwai-Man Luk, Senior Member, IEEE, Kai-Fong Lee, Fellow, IEEE, and Richard Q. Lee, A Broad-Band U-Slot Rectangular Patch Antenna on a Microwave Substrate, IEEE TRANSACTIONS ON ANTENNAS AND PROPAGATION, VOL. 48, NO. 6, JUNE 2000

[3] H. F. AbuTarboush, H. S. Al-Raweshidy and R. Nilavalan, Bandwidth Enhancement for Microstrip Patch Antenna Using Stacked Patch and Slot, 978-1-4244-4396-3/09 (C2009 IEEE

[4] Siddiqui Naushad Ather ${ }^{1}$, Rajesh Kumar Verma ${ }^{2}$,P.K.Singhal ${ }^{3}$,Bandwidth Enhancement for Truncated Rectangular Microstrip Antenna Using Stacked Patches and Defected Ground Structure, 2013 5th International Conference on Computational Intelligence and Communication Networks 975-0-7695-5069-5/13,2013 IEEE DOI10.1109/CICN.2013.21

[5] Mohamed Nabil Srifi, Mourad Meloui and Mohamed Essaaidi, Rectangular Slotted Patch Antenna for 5-6GHz Applications, INTERNATIONAL JOURNAL OF MICROWAVE AND OPTICAL TECHNOLOGY, pp 52-57, VOL.5 NO.2 MARCH 2010.

[6] Chao Deng, Yong-jun Xie, and Ping Li, CPW-Fed Planar Printed Monopole Antenna With Impedance Bandwidth Enhanced, IEEE ANTENNAS AND WIRELESS PROPAGATION LETTERS, VOL. 8, 2009

[7] David M. Pozar ,'Microwave Engineering', third edition 2010,WILEY

[8] Asok De, N.S. Raghava, Sagar Malhotra, Pushkar Arora, Rishik Bazaz, Effect of different substrates on Compact stacked square Microstrip Antenna, JOURNAL OF TELECOMMUNICATIONS, VOLUME 1, ISSUE 1, FEBRUARY 2010

[9] IE3D User's manual, 1999.Zeland Software, Inc. 